\title{
O CONSUMO CRESCENTE DE AGROTÓXICOS E SUAS IMPLICAÇÕES NA SAÚDE REPRODUTIVA
}

\author{
Jaqueline Nascimento da Silva ${ }^{1}$
}

Patricia Alexandra Antunes ${ }^{2}$

\begin{abstract}
Ana Paula Alves Favareto ${ }^{3}$
\section{RESUMO}

O consumo excessivo de agrotóxicos tem sido um dos principais fatores de agravamento da poluição ambiental. A mobilidade desses compostos no ambiente facilita a contaminação de solos, ar e recursos hídricos, afetando diversas espécies e interferindo na saúde de seres humanos e animais. Considerando a expansão da agricultura no país e o uso desenfreado de praguicidas, este trabalho trata-se de uma exposição dos principais riscos à saúde e fontes de contaminação, enfatizando alguns estudos relacionados a alterações reprodutivas e do desenvolvimento. Dessa maneira faz-se entender a importância de estudos avaliativos de agrotóxicos acerca de seus mecanismos de toxicidade e possíveis efeitos em diferentes doses e vias de exposição.
\end{abstract}

PALAVRAS-CHAVE: Agrotóxicos, Agravos a Saúde, Alterações Reprodutivas e do Desenvolvimento.

\footnotetext{
'Química, UNOESTE, Mestranda do Mestrado em Meio Ambiente e Desenvolvimento Regional, UNOESTE, jaque1562@hotmail.com.

2Doutora em Química Analítica, Professora e Pesquisadora, UNOESTE, antunes@unoeste.br ${ }^{3}$ Doutora em Biologia Celular e Estrutural, Professora e Pesquisadora, UNOESTE, anafavareto@unoeste.br
} 


\title{
THE INCREASING CONSUMPTION OF AGROTOXICS AND ITS IMPLICATIONS ON REPRODUCTIVE HEALTH
}

\begin{abstract}
The overconsumption of agrotoxics has been one of the main factors in worsening environmental pollution. The mobility of these compounds in the environment makes it easier to soil, air and hydric resourcescontamination, affecting several species and interfering with the health of humans and animals. Considering the expansion of agriculture in the country and the unbridled use of pesticides, this work is an exhibition of the main health risks and sources of contamination, emphasizing some studies related to reproductive and development changes. Thus it makes to understand the importance of evaluative studies of agrotoxics about their mechanisms of toxicity and possible effects at different doses and routes of exposure.
\end{abstract}

KEY-WORDS: Agrotoxics, Worsenings to health, Reproductive and Development Changes

\section{EL USO CRECIENTE DE PESTICIDAS Y SUS IMPLICACIONES EM LA SALUD REPRODUCTIVA}

\begin{abstract}
RESUMEN
El consumo excesivo de pesticidas ha sido un factor importante en el empeoramiento de la contaminación ambiental. La movilidad de estos compuestos en el medio facilita la contaminación de los recursos del suelo, aire y agua, que afecta a varias especies e interfiere con la salud de los seres humanos y los animales. Teniendo en cuenta la expansión de la agricultura en el país y el uso desenfrenado de los plaguicidas, esta obra es una exposición de los principales riesgos para la salud y las fuentes de contaminación, dando énfasis en algunos estudios relacionados con los cambios reproductivos y de desarrollo. De este modo se hace para entender la importancia de los estudios de evaluación de los plaguicidas sobre sus mecanismos de toxicidad y los posibles efectos en diferentes dosis y vías de exposición.
\end{abstract}

PALABRAS-CLAVE: Pesticidas, Daños a la Salud, Cambios Reproductivos y de Desarrollo.

\section{INTRODUÇÃO}

O homem faz uso da tecnologia para melhorar a qualidade de vida e aumentar a produtividade, interferindo diretamente nos recursos naturais. Para atender a demanda agroindustrial, produtos são desenvolvidos com o intuito de aumentar ou melhorar a produtividade agrícola, diminuir ou eliminar as interferências causadas por insetos, plantas daninhas, etc. que dificultam o desenvolvimento da 
produção. Segundo Peres, Rozemberg, Lucca (2005, p. 1836) "não se pode negar que a tecnologia no campo proporciona o crescimento em termo de produtividade".

Porém existe uma situação ambivalente, por um lado, a incorporação tecnológica que possibilita o aumento e a diversificação da produção e por outro, o surgimento de novas injúrias à saúde e à segurança daqueles que utilizam tais tecnologias, dos organismos vivos presentes no ambiente e de toda a população. (PERES, ROZEMBERG, LUCCA 2005)

Um dos principais produtos que se enquadram nessa situação ambivalente são os agrotóxicos. Segundo a legislação vigente, agrotóxicos são produtos e agentes de processos físicos, químicos ou biológicos, utilizados nos setores de produção, armazenamento e beneficiamento de produtos agrícolas, pastagens, proteção de florestas, nativas ou plantadas, e de outros ecossistemas e de ambientes urbanos, hídricos e industriais. (BRASIL, 2014)

Os agrotóxicos são desenvolvidos com o intuito de alterar a composição da fauna e flora, eliminando assim efeitos possivelmente nocivos que seres vivos podem causar às culturas. Com a elevada utilização têm ocorrido grandes impactos, pois esses produtos acabam sendo lixiviados, afetando as águas superficiais, os lençóis freáticos, além de afetar os organismos vivos de uma forma geral, podendo até influenciar na saúde do homem (BRASIL, 2002; CARSON, 2010).

Nos últimos três anos o Brasil vem ocupando o lugar de maior consumidor de agrotóxicos no mundo. Os impactos à saúde pública são amplos porque atingem vastos territórios e envolvem diferentes grupos populacionais como trabalhadores em diversos ramos de atividades, moradores do entorno de fábricas e fazendas, além de todos nós que consumimos alimentos e água contaminados. (CARNEIRO, 2012)

Diversas substâncias utilizadas na agricultura podem apresentar ação teratogênica, mutagênica e carcinogênica (FEBER; CABRAL, 1991; IARC, 1991). Vários estudos demonstram que os agrotóxicos podem provocar malformações congênitas após exposição in útero ou alterações do sistema reprodutor (AMARANTE JUNIOR et al., 2002; DALLEGRAVE, 2003; SARPA et al., 2007; MATHIAS et al., 2012). Diante disto, a avaliação do potencial toxicológico (periculosidade) de 
praguicidas pode fornecer informações importantes para a implementação de políticas governamentais de saúde pública, que regularizem sua utilização em níveis seguros para exposição humana (MORRISON et al.,1992; WEISENBURGER, 1993)

Desta forma, estudos relacionados a alterações em organismos vivos causadas por agrotóxicos são de extrema importância para a compreensão das interações que ocorrem entre essas substâncias químicas e os organismos vivos. Esses estudos podem contribuir para que se avance na identificação dos mecanismos que levam a toxicidade e no desenvolvimento de tratamentos e medidas preventivas de intoxicações. Além disso, contribui na tomada de decisões do poder público na criação de leis e políticas públicas que visem o bem estar da população que está exposta aos agrotóxicos.

\section{AGROTÓXICOS: FUNÇÕES E IMPACTOS AMBIENTAIS}

Os agrotóxicos são biocidas usados na agricultura com vistas a eliminar alguma forma de vida. São venenos aplicados para exterminar as pragas, plantas concorrentes e doenças das plantas, esses produtos se constituem em um dos maiores poluentes químicos lançados em nosso planeta. São utilizados também em setores diversos, como no controle de pragas que atingem os jardins, de vetores implicados nas endemias vetoriais regionais, no ambiente intradomiciliar para eliminar insetos, no controle de populações de ratos na região urbana e de formigas, na erradicação de vegetação ao longo de ferrovias e rodovias, no setor pecuário (GRISÓLIA, 2005).

No Brasil, estas substâncias são referidas como praguicidas, defensivos agrícolas e mais recentemente de agrotóxicos. Esta última nomenclatura somente foi adotada após a sanção da Lei Federal n. 7.802, de 11 de julho de 1989, atualmente regulamentada pelo Decreto 4.074, de 04 de janeiro de 2002, que torna claro o caráter danoso destas substâncias capazes de destruir vida animal e vegetal, características que ficam totalmente mascaradas em uma denominação de caráter positivo como a de "defensivos agrícolas". Além disso, o termo "defensivos agrícolas", 
utilizado pela Legislação brasileira até a Constituição de 1988 (publicada em 1989), excluía, pelo seu próprio significado, todos os agentes utilizados nas campanhas sanitárias urbanas para controle de vetores. $\mathrm{O}$ termo agrotóxico é mais ético, honesto e esclarecedor, tanto para os agricultores, como para os consumidores (PERES; MOREIRA; DUBOIS, 2003).

Os agrotóxicos podem ser classificados de diversas maneiras, uma delas é de acordo com o modo de ação do ingrediente ativo no organismo alvo, podendo ser: acaricidas (ação em ácaros), bactericidas (ação em bactérias), fungicidas (ação em fungos), inseticidas (ação em insetos), herbicidas (ação em plantas daninhas), algicidas (algas), rodenticidas (roedores), entre outros. Outra maneira é a classificação toxicológica, que indica que o agrotóxico é de maior ou menor periculosidade. A Tabela 1 apresenta essa classificação.

Tabela 1- Classe toxicológica e cor da faixa no rótulo de produtos agrotóxicos

\begin{tabular}{c|c|c} 
Classe Toxicológica & Toxicidade do Produto & Faixa Indicativa de Cor \\
\hline I & Extremamente tóxicos & Vermelha \\
\hline II & Altamente tóxicos & Amarela \\
\hline III & Mediamente Tóxicos & Azul \\
\hline IV & Pouco Tóxicos & Verde \\
\hline
\end{tabular}

Fonte: OPAS/OMS, 1997, p. 19

De acordo com a classificação toxicológica, quanto menor a classe maior será o perigo de dano ao meio ambiente, e com isso a cor da faixa apresentada nos rótulos varia de vermelha a verde, por exemplo: a Classe I apresenta maior perigo e é caracterizada pela faixa vermelha.

Outra forma de classificar é dada pela $\mathrm{DL}_{50}$, uma medida padrão de toxicidade aguda, onde são realizados testes com animais, e de acordo com o modo de exposição (via oral, dérmica ou respiratória) esses valores podem variar, estipulando a dose/concentração letal para $50 \%$ da população exposta, ou seja, a dose requerida para matar $50 \%$ da população de animais em teste. Então quanto menor o valor da 
$\mathrm{DL}_{50}$ maior será a toxicidade, apresentando maior risco ao ambiente e aos seres humanos. (BAIRD, 2002)

A utilização de agrotóxicos na agricultura teve início na década de 1920, tendo sua aplicação se expandido por ocasião da $2^{\mathrm{a}}$ Guerra Mundial, quando foram utilizados como arma química. O uso dessas substâncias se tornou mais amplo a partir desse período. No Brasil, foram inicialmente usados nos programas de saúde pública, com vistas ao controle de vetores. (ROQUETO, 2012)

Os agrotóxicos foram introduzidos na agricultura com o intuito de promover a modernização e elevar o grau de produtividade do setor. Havia interesses econômicos, por parte dos grandes proprietários, em promover o abastecimento de alimentos às cidades e indústrias. Desde o século XVI a adubação com esterco animal e com outros meios de origem orgânica tornava-se a cada dia mais inviável, pois existia uma intencionalidade em fornecer matéria-prima em grande quantidade para o setor industrial e para o mercado. (ROQUETO, 2012)

O estado de São Paulo se destacou em 2006 como o maior consumidor brasileiro de agrotóxicos, representando $20,6 \%$ do faturamento total de agrotóxicos negociados no Brasil. Sendo a classe de herbicidas a mais utilizada, sendo $43,1 \%$ do faturamento total do estado. As vendas estão destinadas principalmente ao cultivo de cana-de-açúcar, soja e milho, seguida pelas seguintes classes: inseticidas $(30,1 \%)$, fungicidas $(16,6 \%)$, acaricidas $(7,6 \%)$ entre outras $(2,6 \%)$ (FERREIRA; VEGRO; CAMARGO, 2008).

$\mathrm{O}$ uso incorreto de produtos químicos em áreas agrícolas representa grande ameaça ao meio ambiente. A natureza orgânica das moléculas de muitos produtos permite sua degradação, sendo necessário estudar os destinos e as consequências do transporte destas moléculas e seus resíduos (MATTOS; SILVA, 1999). Do ponto de vista ambiental, a crescente utilização de insumos químicos poderá acarretar consequências catastróficas, entre elas a contaminação de água potável, que atualmente é uma grande preocupação mundial. Parte dessa preocupação se deve ao fato de a maior parte dos biocidas produzidos acabarem atingindo a água, seja por deriva durante a aplicação, resíduos de embalagens vazias, lavagem de 
equipamentos, ou, até mesmo, efluentes de indústrias de biocidas. (ROMERO et al., 2004)

Nas últimas décadas, os problemas ambientais têm se tornado cada vez mais críticos e frequentes, principalmente devido ao crescimento populacional e ao aumento da atividade industrial. Esses problemas refletem-se na poluição do solo e das águas superficiais e subterrâneas, tanto por escoamento, por infiltração e percolação, como por lançamentos de poluentes atmosféricos (SOTTORIVA; TAUCHERT; PERALTA-ZAMORA, 2002).

A contaminação de solos e águas subterrâneas por compostos orgânicos voláteis tem sido destaque nas últimas décadas, principalmente em função da frequência com que episódios de contaminação são verificados e da gravidade com que o meio ambiente é afetado (TIBURTIUS; PERALTA-ZAMORA; LEAL, 2005).

\section{AGROTÓXICOS: UTILIZAÇÃO E AGRAVOS A SAÚDE}

Além da contaminação ao meio ambiente, outra polêmica relacionada aos agrotóxicos é os danos causados a saúde. As estimativas da incidência de problemas de saúde humana relacionados com a utilização de praguicidas é muito variável. Os danos para o organismo humano começaram a ser noticiados a partir dos anos sessenta, com relatos de casos de intoxicação por organoclorados entre trabalhadores rurais. Esta classe passou a ser proibida pela legislação de vários países. Atualmente, estima-se que entre 500 mil e 2,9 milhões de pessoas no mundo são envenenadas anualmente, com uma taxa de fatalidade de $1 \%$, aproximadamente (JEYEARATNAM, 1985). A maioria dos casos de doenças relacionadas a praguicidas envolve o uso de organoclorados e os organofosforados que possuem atividade neurotóxica. (US CONGRESS OFFICE OF TECHNOLOGY ASSESSMENT, 1990; ARAÚJO, 2000)

A ampla utilização de agrotóxicos, o desconhecimento dos riscos associados a sua utilização, o consequente desrespeito às normas básicas de segurança, a livre comercialização, a grande pressão comercial por parte das empresas distribuidoras e 
produtoras e os problemas sociais encontrados no meio rural constituem importantes causas que levam ao agravamento dos quadros de contaminação humana e ambiental observados no Brasil. A esses fatores podem ser acrescentados a deficiência da assistência técnica ao homem do campo, a dificuldade de fiscalização do cumprimento das leis e a culpabilização dos trabalhadores como contribuintes para a consolidação do impacto sobre a saúde humana, decorrente da utilização de agrotóxicos, como um dos maiores problemas de saúde pública no meio rural, principalmente nos países em desenvolvimento (PIMENTEL, 1996; PERES, 1999; OLIVEIRA-SILVA; MEYER; MOREIRA, 2000).

A dose de aplicação está diretamente relacionada com as contaminações de alimentos, que são consumidos pelas pessoas, podendo causar possíveis danos à saúde. Muitas vezes, os produtos são utilizados excessivamente, permanecendo como resíduos nos alimentos, sendo que alguns possuem seus limites máximos estabelecidos superados. Outras vezes, muitas substâncias proibidas (restrita naquela cultura, ou no Brasil) são utilizadas em várias culturas, como é evidenciado pelo Programa de Análise de Resíduos de Agrotóxicos em Alimentos (PARA) da Agência de Nacional de Vigilância Sanitária (ANVISA), que avalia os níveis de resíduos de agrotóxicos nos alimentos in natura que chegam à mesa do consumidor (ANVISA, 2011).

Um terço dos alimentos consumidos cotidianamente pelos brasileiros está contaminado pelos agrotóxicos, segundo análise de amostras coletadas em todas as 26 Unidades Federadas do Brasil, realizadas pelo Programa de Análise de Resíduos de Agrotóxicos em Alimentos (PARA) da ANVISA (2011), onde 63\% das amostras analisadas apresentaram contaminação por agrotóxicos, sendo que $28 \%$ apresentaram ingredientes ativos não autorizados (NA) para aquele cultivo e/ou ultrapassaram os limites máximos de resíduos (LMR) considerados aceitáveis. Outros $35 \%$ apresentaram contaminação por agrotóxicos, porém dentro destes limites. Se estes números já delineiam um quadro muito preocupante do ponto de vista da saúde pública, eles podem não estar ainda refletindo adequadamente as dimensões do problema, seja porque há muita ignorância e incerteza científicas embutidas na 
definição destes limites, seja porque os 37\% de amostras sem resíduos referem-se aos ingredientes ativos pesquisados, 235 em 2010 - o que não permite afirmar a ausência dos demais (cerca de 400). (CARNEIRO, 2012)

Destaca-se também que o nível médio de contaminação das amostras dos 26 estados brasileiros está distribuído pelas culturas agrícolas da seguinte maneira: pimentão $(91,8 \%)$, morango $(63,4 \%)$, pepino $(57,4 \%)$, alface $(54,2 \%)$, cenoura $(49,6 \%)$, abacaxi $(32,8 \%)$, beterraba $(32,6 \%)$ e mamão $(30,4 \%)$, além de outras culturas analisadas e registradas com resíduos de agrotóxicos (ANVISA, 2011). tomate, apesar e ser considerado uma fonte importante de contaminação, aparece em décimo lugar no ranking de alimentos contaminados, com 16,3\%.

O uso de um ou mais agrotóxicos em culturas para as quais eles não estão autorizados, sobretudo daqueles em fase de reavaliação ou de descontinuidade programada devido à sua alta toxicidade, apresenta consequências negativas na saúde humana e ambiental. Uma delas é o aumento da insegurança alimentar para os consumidores que ingerem o alimento contaminado com ingredientes ativos (las), pois esse uso, por ser absolutamente irregular, não foi considerado no cálculo da Ingestão Diária Aceitável (IDA), sendo que esta insegurança se agrava à medida que esse agrotóxico é encontrado em vários alimentos consumidos em nossa dieta cotidiana. (CARNEIRO, 2012)

Além da contaminação direta do alimento, há outras fontes de contaminação que são expressivas no país, como por exemplo, o cultivo da cana-de-açúcar. Segundo um levantamento realizado por Armas et al (2007) na região da sub-bacia do Rio Corumbataí (integrante da bacia do Rio Piracicaba), no período de janeiro de 2000 a dezembro de 2003 85\% do volume total de glifosato, atrazina, ametrina, 2,4-D, metribuzim, diuron e acetocloro consumidos foram destinados a cana-de-açúcar. Outro estudo realizado entre 2004 e 2005 na mesma sub-bacia detectaram em amostras de água os herbicidas hexazinona, glifosato, clomazona e do grupo das triazinas (ametrina, atrazina e simazina), sendo a cultura de maior expressão a de cana-de-açúcar. Os níveis de detecção mais elevados foram das triazinas: ametrina 0,7-2,9 $\mu \mathrm{g} \cdot \mathrm{L}^{-1}$, atrazina 0,6-2,7 $\mu \mathrm{g} \cdot \mathrm{L}^{-1}$ e simazina 0,3-0,6 $\mu \mathrm{g} \cdot \mathrm{L}^{-1}$. (ARMAS et. al 2005). 
Outra possível fonte de contaminação importante no Estado de São Paulo, é a produção de seringueira, a principal fonte de borracha natural do mundo. Lima (1994) apresenta em um estudo de controle químico de plantas invasoras de seringais que os principais agrotóxicos utilizados são o diuron, glifosato, 2-4-D e metalocloro. Atualmente outros agrotóxicos entram nessa lista: benomyl, carbendazim, malathion e endosulfan (MELO et al, 2008). Outras substâncias químicas dentre as variedades de praguicidas encontradas no mercado de defensivos agrícolas, encontram-se o tiofanato metílico e o clorotalonil. Esses compostos fazem parte da formulação do composto Cerconil $W P^{\circledR}$, um fungicida amplamente utilizado nos seringais para eliminação e prevenção da Antracnose.

O clorotalonil pode levar a sinais clínicos de intoxicação inespecíficos que podem incluir anorexia, depressão, fraqueza e diarréia. $O$ produto tem um efeito catártico, o qual, aparentemente, é devido à irritação do trato gastrointestinal. Já o tiofanato metílico apresenta sinais e sintomas de intoxicação em animais de experimentação, incluindo tremores, convulsões tônico-clônicas, diminuição do ritmo respiratório, letargia e midríase. A inalação e manipulação excessiva podem produzir irritação do trato respiratório, pele e mucosas. Sangramento nasal e lacrimejamento já foram observados em ratos. (IHARA, 2008)

Mesmo que alguns dos ingredientes ativos possam ser classificados como medianamente ou pouco tóxicos - baseado em seus efeitos agudos - não se pode perder de vista os efeitos crônicos que podem ocorrer meses, anos ou até décadas após a exposição, manifestando-se em várias doenças como cânceres e distúrbios endócrinos, neurológicos e mentais. (CARNEIRO, 2012)

Dentre os possíveis efeitos adversos causados à saúde humana e animal, destacam-se as alterações reprodutivas e do desenvolvimento embriofetal, muitas vezes, associadas à desregulação endócrina causada por agrotóxicos.

A exposição intrauterina a estes compostos pode causar restrição de crescimento e o aumento da incidência de malformações fetais (MATSUMOTO et al., 2010; WICKERHAN et al., 2012). Já no sistema reprodutor masculino, alterações como diminuição de espermatozóides e aumento de espermatozóides danificados 
(apresentando dano do DNA) são exemplos que podem ocorrer em animais expostos a esses compostos. (BAIRD, 2002; DALLEGRAVE, E. et al. 2007; GHISELLI; JARDIM, 2007; SPIRO; STIGLIANI, 2008; AKCHA; SPAGNOL; ROUXEL, 2012;. FEYZI-DEHKHARAGNI et al. 2012).

Estudos de exposição in utero, durante o período da organogênese, aos praguicidas Glifosato-Roundup (DALLEGRAVE, 2003), ácido 2,4-diclorofenoxiacético (2,4-D) (AMARANTE JUNIOR et al. 2002), trifenil hidróxido de estanho (SARPA, et al., 2007) e dinoseb (MATSUMOTO et al., 2010) demonstraram o aparecimento de anormalidades esqueléticas e atraso de desenvolvimento ósseo em fetos de rato e camundongo.

Khera et al. (1979) administraram dose de $500 \mathrm{mg} / \mathrm{kg}$ de Diuron $(80 \%$ de pureza) dissolvido em óleo, em ratas prenhes do $6^{\circ}$ ao $15^{\circ}$ dia de gestação e observaram diminuição do peso materno e dos fetos. No mesmo experimento, doses de 250 e $500 \mathrm{mg} / \mathrm{kg}$ aumentaram a incidência de fetos com malformações. No entanto, a exposição de ratos adultos ao Diuron em doses de 125 e $250 \mathrm{mg} / \mathrm{kg} / \mathrm{dia}$, por 30 dias consecutivos, não resultou em alterações reprodutivas evidentes (FERNANDES et al., 2007).

Estudo de Wilson et al. (2009) demonstrou que a exposição intrauterina ao linuron pode acarretar inibição da produção de testosterona fetal, reduzindo os níveis androgênicos durante o período crítico da diferenciação sexual. Já a exposição maternal durante a organogênese ao clorotanolil em diferentes doses afeta principalmente o número de fetos vivos, número de reabsorções precoces e o peso fetal (FARAG; ABDEL-ZAHER; OKAZY, 2006).

A exposição gestacional à atrazina pode causar alterações de desenvolvimento devido à possibilidade de transferência placentária. Dentre as possíveis alterações fetais destacam-se: a redução da dopamina fetal (LI et al., 2014) e implicações pós-natal como aumento da incidência de morte pós-natal (FRAITES et al., 2011) e atraso da instalação da puberdade (ROSEMBERG et al., 2007; DAVIS et al., 2011). 
Um estudo realizado com metolacloro isolado e em mistura com outros praguicidas, em doses de que simulam os graus de exposição observados durante o manuseio de praguicidas, inalação ou ingestão de água contaminada, demonstrou um aumento da apoptose de embriões em fase de pré-implantação, com consequente redução da taxa de desenvolvimento do blastocisto. Este estudo revelou que a lesão induzida por praguicidas pode ocorrer precocemente no desenvolvimento, mesmo em concentrações consideradas baixas e que provavelmente não levariam a efeitos adversos à saúde humana (GREENLEE; ELLIS; BERG, 2004).

\section{CONCLUSÃO}

Assim podemos concluir que a crescente utilização de agrotóxicos é uma realidade preocupante para o meio ambiente e para a saúde humana e animal. $\mathrm{O}$ avanço desenfreado da agricultura, seguido de pouca preocupação, de algumas partes, com as causas e efeitos, gera um debate entre o desenvolvimento e a preservação ambiental e bem estar dos seres vivos.

A exposição a praguicidas de diversas maneiras, traz consigo um vasto número de contaminações que interferem na saúde em um todo. As altas toxicidades de alguns compostos são capazes de causar alterações nos organismos vivos das mais variadas formas. Estudos toxicológicos afim de detectar possíveis alterações reprodutivas trazem resultados alarmantes.

Embora alguns agrotóxicos sejam amplamente estudados, muitos ainda não possuem informações suficientes quanto aos mecanismos de toxicidade e possíveis efeitos em diferentes doses e vias de exposição. Dessa forma, é de grande importância estudos que identifiquem a possível toxicidade desses compostos e os possíveis danos causados a saúde do ser humano e de animais.

\section{REFERÊNCIAS}


AKCHA, F.; SPAGNOL, C.; ROUXEL, J. Genotoxicity of diuron and glyphosate in oyster spermatozoa and embryos. Aquatic Toxicology, Amsterdan; v. 106-107, p. 104-113, 2012.

AMARANTE JUNIOR, O.P. et al. Revisão das propriedades, usos e legislação do Ácido 2,4diclorofenoxiacético (2,4-D). Cad. Pesq. v. 13, n. 1, p. 60-70, 2002.

ANVISA- Agência Nacional de Vigilância Sanitária. Programa de Análise de Resíduos de Agrotóxicos em Alimentos (PARA) - Relatório de Atividades de 2010. Brasília, Dezembro, 2011. Disponível em: <

http://portal.anvisa.gov.br/wps/content/Anvisa+Portal/Anvisa/Inicio/Agrotoxicos+e+Toxicologia/Assuntos $+d e+$ Interesse/Programa+de+Analise+de+Residuos+de+Agrotoxicos+em+Alimentos>. Acesso em ago 2013.

ARAÚJO, A. J. et al. Meio Ambiente, Saúde e Trabalho. CUT-RJ, Comissão de Meio Ambiente. $1^{\mathrm{a}}$ ed. Rio de Janeiro, 2000.

ARMAS, E.D. et al. Diagnóstico espaço-temporal da ocorrência de herbicidas nas águas superficiais e sedimentos do rio Corumbataí e principais afluentes. Química Nova, São Paulo; v. 30, n. 5, p. 11191127, 2007.

ARMAS, E.D. et al. Uso de agrotóxicos em cana-de-açúcar na bacia do rio Corumbataí e o risco de poluição hídrica. Química Nova, São Paulo; v. 28, n. 6, p. 975-982, 2005.

BAIRD, C. Química Ambiental. 2. ed. Bookman: Porto Alegre, 2002, cap. 6.

BRASIL. Ministério do Meio Ambiente. Segurança Química. Agrotóxicos. Brasília (DF), 2014. Disponível em: <http://www.mma.gov.br/seguranca-quimica/agrotoxicos>. Acesso em ago 2014.

BRASIL. Lei $n^{\circ} 7.802$ de 11 de julho de 1989 - Decreto n. ${ }^{\circ} 4.074$, de 4 de janeiro de 2002. Dispõe sobre a pesquisa, a experimentação, a produção, a embalagem e rotulagem, o transporte, o armazenamento, a comercialização, a propaganda comercial, a utilização, a importação, a exportação, o destino final dos resíduos e embalagens, o registro, a classificação, o controle, a inspeção e a fiscalização de agrotóxicos, seus componentes e afins. Diário Oficial, 08 de janeiro de 2002.

CARNEIRO, F. F. et al. Dossiê ABRASCO: um alerta sobre os impactos dos agrotóxicos na saúde. Rio de Janeiro: $\quad$ ABRASCO; $2012 . \quad$ Disponível em: http://www.abrasco.org.br/UserFiles/File/ABRASCODIVULGA/2012/DossieAGT.pdf>. Acesso em ago 2014.

CARSON, R. Primavera Silenciosa. 1 ed. São Paulo: Gaia, 2010.

DALLEGRAVE, E. Toxicidade reprodutiva do herbicida glifosato-Roundup em ratos Wistar. Tese de Doutorado. Universidade Federal do Rio Grande do Sul. Faculdade de Veterinária. Programa de PósGraduação em Ciências Veterinárias. 2003.2014. <http://www.lume.ufrgs.br/handle/10183/2819>. Acesso em maio 2014.

DALLEGRAVE, E. et al. Pre- and postnatal toxicity of the commercial glyphosate formulation in Wistar rats. Archives of Toxicology, Berlin; v. 81, n. 9, p. 665-673, 2007.

DAVIS, L. K. et al. The effects of prenatal exposure to atrazine on pubertal and postnatal reproductive indices in the female rat. Reprod Toxicol. 2011 Jul;32(1):43-51. doi: 10.1016/j.reprotox.2011.04.004. Epub 2011 Apr 20. 
FARAG, A. T.; ABDEL-ZAHER, T.; OKAZY, A. E. Embryotoxicity of Oral Administered Chlorothalonil in Mice. Birth Defects Research ( Part B) 77: 104-109, 2006.

FEBER, A.; CABRAL, R. Toxic epidemics caused by alimentary exposure to pesticides: a review. Food Additives Contam., v.8, p.755-776, 1991.

FERNANDES, G. S et al. Reproductive effects in male rats exposed to diuron. Reprod Toxicol. 2007 Jan;23(1):106-12.

FERREIRA, C.R.R.P.; VEGRO, C.L.R.; CAMARGO, M.L.B. Defensivos agrícolas: rumo a uma retomada sustentável. Análises e Indicadores de Agronegócio, São Paulo; v. 3, n. 2, 2008

FEYZI-DEHKHARGANI, S. et al. Atrazine in sub-acute exposure results in sperm DNA disintegrity and nuclear immaturity in rats. Veterinary Research Forum, Paris; V. 3, n. 1, p. 19-26, 2012.

FRAITES, M. J. et al. Gestational atrazine exposure: effects on male reproductive development and metabolite distribution in the dam, fetus, and neonate. Reprod Toxicol. 2011 Jul;32(1):52-63. doi: 10.1016/j.reprotox.2011.04.003. Epub 2011 Apr 17.

GHISELLI, G.; JARDIM, W. F. Interferentes endócrinos no ambiente. Química Nova, São Paulo; v. 30, n. 3, p. 695-706, 2007.

GREENLEE, A. R.; ELLIS, T. M.; BERG, R. L. Low-dose agrochemicals and lawn-care pesticides induce developmental toxicity in murine preimplantation embryos. Environmental Health Perspectives. Vol. 112, n. 6, p. 703-709, 2004.

GRISÓLIA, K. C. Estudos da mutagênicidade dos agrotóxicos. Agrotóxicos: mutações, reprodução e câncer. 1. ed. Brasília, DF: Ed. UnB.

IARC. Monographs on the evaluation of carcinogenic risk to humans. Occupational exposures in insecticide application, and some pesticides. Lyon: IARC Scientific Publications. v. 53, 1991.

IHARA. Ficha de Informações de Segurança de Produto Químico: Cerconil WP. 2008. Disponível em: <http://www.ihara.com.br/upload/produtos/fispq/1269463260.pdf>. Acesso em maio de 2014.

JEYEARATNAM, J. Health Problems od Pesticides Usage in the Third World. Br J Ind. Med, 1985.

KHERA, K.S.; WHALEN, C.; TRIVETT, G. e ONGERS, G. Teratogenicity studies on pesticide formulations of dimethoate, Diuron, and lindane in rats. Bull. Environ. Contam. Toxicol. 22: 522, 1979.

LI, Y. et al. Age-dependent dopaminergic dysfunction following fetal exposure to atrazine in SD rats. Environ Toxicol Pharmacol. 2014 May;37(3):1275-82.

MATSUMOTO, M. et al. Prenatal developmental toxicity of gavage or feeding doses of 2-sec-butyl-4,6dinitrophenol in rats. Reprod Toxicol. 2010 Jun;29(3):292-7. doi: 10.1.

MATTOS, L.M.; SILVA, E. F. Influência das propriedades de solos e de agrotóxicos no potencial de contaminação de solos e águas subterrâneas. Agrotóxicos: Revista Ecotoxicológica e Meio Ambiente, Curitiba, v. 9, p.103-124, jan./dez. 1999.

MELO, D. F. et al. Compatibilidade de Dicyma pulvinata com defensivos agrícolas e eficiência do biocontrole do mal-das-folhas da seringueira em campo. Pesquisa agropecuária brasileira, Brasília, v.43, n.2, p.179-185, fev. 2008. 
MORRISON, H. I. et al. Herbicides and cancer. J. Natl. Cancer Inst. v. 84, p. 1866-1874, 1992.

OLIVEIRA-SILVA, J. J.; MEYER, A.; MOREIRA, J. C. Cholinesterase activities determination in frozen blood samples: an improvement to the occupational monitoring in developing countries. Human and Environmental Toxicology 19:173-177, 2000.

OPAS (Organização Pan-americana da Saúde). Manual de vigilância da saúde de populações expostas a agrotóxicos. Ministério da Saúde, Secretaria de Vigilância Sanitária. Brasília: Organização Pan-americana da Saúde/OMS, $1997 . \quad$ Disponível em: <http://bvsms.saude.gov.br/bvs/publicacoes/livro2.pdf>. Acesso em abr. 2013.

PERES, F. É veneno ou é remédio? Os desafios da comunicação rural sobre agrotóxicos. Dissertação de mestrado. Escola Nacional de Saúde Pública, Fundação Oswaldo Cruz. Rio de Janeiro, 1999. Disponível <http://scholar.google.com.br/scholar?q=agrotoxicos+e+maleficios+a+sa\%C3\%BAde\&btnG=\&hl=ptBR\&as_sdt=0\%2C5>. Acesso em ago 2014.

PERES, F; MOREIRA, J.C; DUBOIS, G.S. Agrotóxicos, Saúde e Ambiente: uma introdução ao tema. p. 21-41. É veneno ou é remédio? 1ª edição, Rio de Janeiro. Editora Fiocruz. 2003.

PERES, F.; ROZEMBERG, B.; LUCCA, S. R. Percepção de riscos no trabalho rural em uma região agrícola do estado do Rio de Janeiro, Brasil: agrotóxicos, saúde e meio ambiente. Caderno de Saúde Pública, Rio de Janeiro, v. 21, n. 6, p. 1836-1844, nov./dez., 2005

PIMENTEL, D. Green revolution agriculture and chemical hazards. The Science of the Total Enviromment, 188(1):S86-S98. 1996.

ROMERO, A. H. H. et al. Marine Pollution Bulletin, 2004, 48, 1130. Disponível em: <http://www.unaerp.br/index.php/documentos/692-marco-antonio-roqueto/file>. Acesso em maio de 2014.

ROSENBERG, B. G. et al. Gestational exposure to atrazine: effects on the postnatal development of male offspring. J Androl. 2008 May-Jun;29(3):304-11. Epub 2007 Oct 31.

ROQUetO, M. A. Estudo da Degradação do Fungicida Tiofanato Metílico em Meio Aquoso por Processos Oxidativos Avançados H2O2/UV Fenton e Fenton/UV. Universidade de Ribeirão Preto, 2012. Disponível em: <http://www.unaerp.br/index.php/documentos/692-marco-antonio-roqueto/file>. Acesso em maio de 2014.

SARPA, M. et al. Developmental toxicity of triphenyltin hydroxide in mice. Regul. Toxicol. Pharmacol., v. 49, n. 1, p. 43-52, 2007.

SOTTORIVA, P. R. S.; TAUCHERT, E.; PERALTA-ZAMORA, P. Estudo comparativo de processos Fenton e foto-fenton utilizando luz visível e ultravioleta próxima na degradação de corantes reativos. VI Simpósio Ítalo brasileiro de Engenharia Sanitária e Ambiental. Vitória - ES. set. 2002.

SPIRO, T. G.; STIGLIANI, W. M. Química Ambiental. 2. ed. São Paulo: Pearson Prentice Hall, 20082009

TIBURTIUS, E. R. L.; PERALTA-ZAMORA, P.; LEAL, E. S. Degradação do BTXS via processos oxidativos avançados. Química Nova. Vol. 28, n.1, 61-64, 2005. 
US CONGRESS OFFICE OF TECHNOLOGY ASSESSMENT. Identifying and controlling poisons of the nervous system. In: Fundamentals of neurotoxicity. Chapter 3, Office of Technology Assessment. April $1990 . \quad$ Disponível em: <http://memorialapodi.com.br/biblioteca/agrotoxicosregioes/docs/Artigo\%20,\%20Exposicao\%20Multipla \%20a\%20Agrotoxicos $\% 20$ e $\% 20$ Efeitos $\% 20$ a\%20Saude\%20Nova\%20Friburgo,\%20RJ\%20,\%20Alberto \%20Araujo\%20et\%20al\%20,\%2030.08.2006.pdf> . Acesso maio de 2013.

WEISENBURGER, D. Perspective in pathology: human health effects of agrichemical use. Hum. Pathol. v. 24, p. 571-576, 1993.

WICKERHAN, E. L. et al. Reduced birth weight in relation to pesticide mixtures detected in cord blood of full-term infants. Environ Int. 2012 October 15; 47: 80-85. doi:10.1016/j.envint.2012.06.007.

WILSON, V. S. et al. The herbicide linuron reduces testosterone production from the fetal rat testis during both in utero and in vitro exposures. Toxicol Lett. 2009 Apr 25;186(2):73-7. doi: 10.1016/j.toxlet.2008.12.017. Epub 2009 Jan 9. 